\title{
Bonding phase of amorphous silicate gas-tight seals for electrode-supported SOFCs
}

\author{
Seiichi Suda, Koichi Kawahara and Kaori Jono \\ 2-4-1 Mutsuno, Atsuta-ku, Nagoya 456-8587, Japan \\ Fax: 81-52-871-3500, e-mail: suda@jfcc.or.jp
}

\begin{abstract}
Electrode-supported SOFCs exhibit highly electrochemical performance but they require gas-tight sealing between porous electrodes. Conventional sealing materials can sufficiently seal with dense materials such as ceramics and metals, but the sealing materials were much penetrated into porous electrodes and excess penetration caused severe gas-leakage. We have prepared insulating flexible sheets to realize gas-tight sealing against porous SOFC electrodes during fusion at $800^{\circ} \mathrm{C}$. Amorphous $\mathrm{Na}_{2} \mathrm{O}-\mathrm{SiO}_{2}$ spherical particles (NS particles) and amorphous $\mathrm{SiO}_{2}$ particles ( $\mathrm{S}$ particle) were synthesized by sol-gel method, and thick sheets containing NS and $\mathrm{S}$ particles were obtained by tape-casting method. Porous $\mathrm{La}_{0.6} \mathrm{Sr}_{0.4} \mathrm{Co}_{0.2} \mathrm{Fe}_{0.8} \mathrm{O}_{3}$ (LSCF) ceramics were used as a porous electrode to investigate penetration of sealing materials and identification of bonding phases. Fusion of the sheet against porous LSCF at $800^{\circ} \mathrm{C}$ resulted in gas-tight sealing and the formation of $\mathrm{NaLa}_{9}\left(\mathrm{SiO}_{4}\right)_{6} \mathrm{O}_{2}$ (NLSO) phase. The formation of NLSO phase was controlled by the addition of S particles. TEC of NLSO did not show anomalous profiles which often result in severe cracks and are shown for some glasses at glass transition temperatures. Therefore, the NLSO phase would be valuable as the bonding phase between LSCF and glass seals.

Key words: SOFC, gas-tight seals, silicate glass, bonding phase, insulating flexible sheet
\end{abstract}

\section{INTRODUCTION}

In Solid oxide fuel cell (SOFC), fuel gas and oxygen gas is allowed to react electrochemically at relatively high temperatures and these electrochemical reactions generate electric power with high fuel utilization and high energy conversion efficiency. High performance and reliable SOFC requires tight gas separation between fuel and air in SOFC cells or stacks using three components; dense electrolyte ceramics that have high oxygen ionic conductivity, dense interconnects that have high electrical conductivity and gas sealing materials. The use of gas seals is essential to avoid burning the fuel gas outside the cells and depressing fuel utilization when interconnects and single cells are stacked alternately.

We can currently use mainly two types of single cells; electrolyte-supported and electrode-supported cells [1, 2]. The former electrolyte-supported cells are fabricated with thick solid electrolyte and thin electrodes of anode and cathode. Glass sealing materials are generally used for electrolyte-supported cells or stacks, and fused between electrolytes and interconnects. Both electrolytes and interconnects are dense ceramics or alloys, and viscous fluid obtained by fusion of glasses sufficiently wettable against dense electrolytes or interconnects to make gas-tight sealing. Generally, electrode-supported cells exhibit higher cell performance than electrolyte-supported cells because electrode-supported cells enable to reduce electrolyte thickness to less than $10 \mu \mathrm{m}$. But electrode-supported cells have some drawbacks, and one of them is high-temperature gas-tight sealing. SOFC electrodes are porous and highly reactive with other materials. When conventional glass sealing materials were used for electrode-supported cells, the viscous fluid obtained by fusion of the glass was much penetrated into the electrode and resulted in lack of sealing. Therefore we have developed glass-derived gas-tight sealing materials for electrode-supported cells or stacks

We prepared two kinds of silicate precursor particles, which are sodium-containing (NS particles) and sodium-free (S particles) silica precursor particles, by sol-gel methods, and the flexible gas-sealing sheets were obtained with the precursor particles by tape casting method [3]. NS particles were synthesized by sol-gel and ion-exchange method, which is promoted the ion exchange between sodium ions and protons of $\mathrm{Si}-\mathrm{OH}$ groups that are formed by hydrolysis of Si alkoxide just before condensation $[4,5]$. An adequate synthesis condition resulted in sodium containing amorphous silicate particles with the $\mathrm{Na} / \mathrm{Si}$ molar ratio of 0.63 . The synthesis conditions are described in elsewhere [3]. Sodium-free silica particles were synthesized with Si alkoxide and $\mathrm{NH}_{3}$ solution by Stöer method [6] .

Relationship between the ratio of NS particles to $S$ particles (NS/S ratio) in the flexible gas-sealing sheets and penetration depth into porous SOFC cathode material was then investigated to seal against porous electrodes. Porous $\mathrm{La}_{0.6} \mathrm{Sr}_{0.4} \mathrm{Co}_{0.2} \mathrm{Fe}_{0.8} \mathrm{O}_{3}$ (LSCF) ceramics were used as SOFC cathode material because LSCF shows high cathodic properties at relatively low temperatures and it is one of the promising cathode materials for intermediate temperature SOFCs [7-9] The flexible sheets with the various compositions were synthesized by tape-casting method and the penetration depths were estimated by scanning electron microscopy (SEM) and energy-dispersive X-ray spectroscopy 


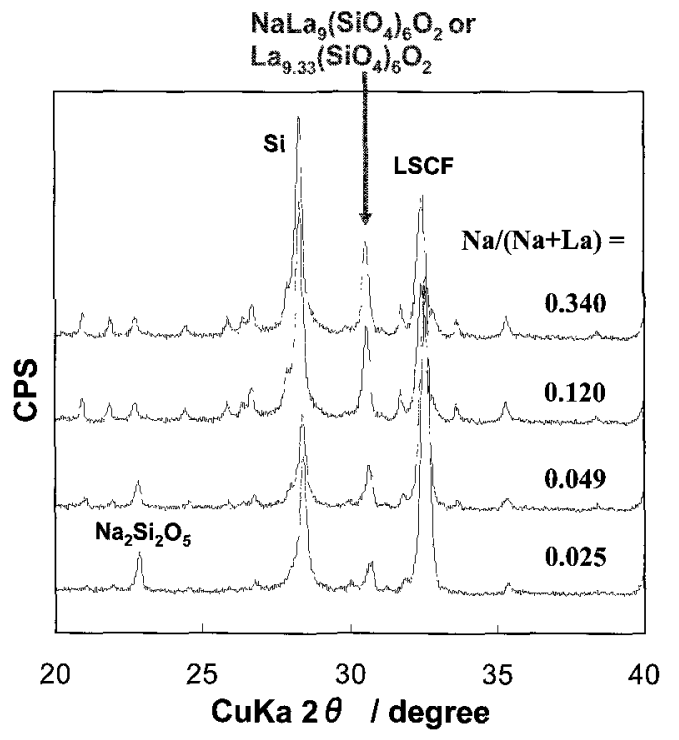

Figure 1. XRD profiles of the powder fused with LSCF and NS particles at $800^{\circ} \mathrm{C}$ for $2 \mathrm{~h}$ in air. Si was used as internal standard for quantitative analysis.

(EDS). The addition of S particle was decreased the penetration into porous LSCF and the penetration depth was controlled at the range from $150 \mu \mathrm{m}$ to $50 \mu \mathrm{m}$ [10].

An adequate particle ratio led to gas-tight sealing against porous LSCF cathode material. However SOFC gas-sealing materials require not only to seal tightly against air or fuel gases but to remain the sealing for several or several dozen thousands hours. If the fused silicate materials led to rigid gas-sealing against relatively reactive $\mathrm{LSCF}$, some bonding phases would be formed in the vicinity of interface between the porous LSCF and the fused silicate sealing materials. The bonding phase between LSCF and the sealing material was then investigated to develop long durable sealing materials for electrode-supported SOFCs.

\section{EXPERIMENTAL}

NS particles and $S$ particles were synthesized by sol-gel and ion-exchange method and Stöber method, respectively as described at the previous section. NS particles and $\mathrm{S}$ particles were mixed at various ratios by ball milling. LSCF power was also mixed with the mixed particles and the mixed powder was calcined at $500^{\circ} \mathrm{C}$ for $12 \mathrm{~h}$ in air, and fused at $800^{\circ} \mathrm{C}$ for $2 \mathrm{~h}$ in air. The fusion resulted in powder dispersing glassy body and the body was ground with an alumina mortar to investigate the bonding phase. The glassy body was also sintered at $650^{\circ} \mathrm{C}$ for $240 \mathrm{~h}$ in air after the fusion to investigate changing amount of the bonding phase with sintering time.

The bonding phase was identified by X-ray diffraction (XRD), and silicon powder was used as an internal standard for quantitative analysis of the bonding phase. Thermal expansions for the bonding phase and LSCF were also estimated with a thermo-mechanical analyzer at temperatures from room temperature to $900^{\circ} \mathrm{C}$.

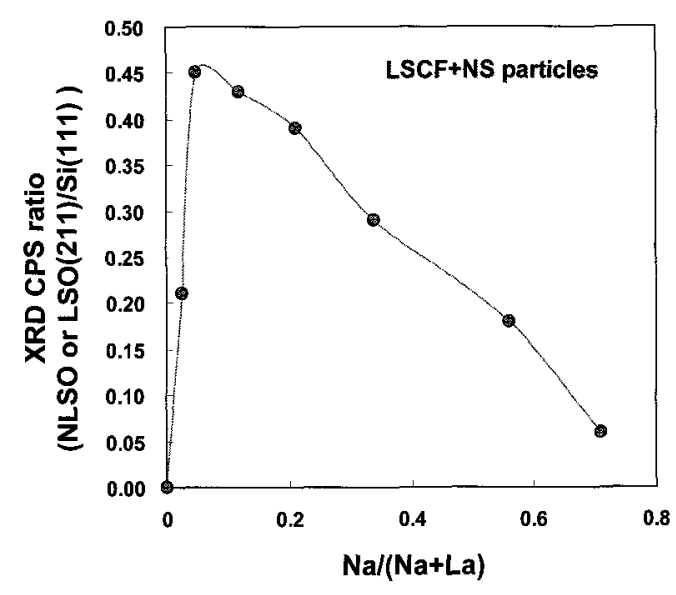

Figure 2. Relationship between NLSO/LSO formation and $\mathrm{Na} /(\mathrm{Na}+\mathrm{La})$ ratios of fused powder.

\section{RESULTS AND DISCUSSION}

The power mixed with NS particles and LSCF was fired at $800^{\circ} \mathrm{C}$. Figure 1 shows XRD profiles of the glassy powder obtained by fusion of NS particles and $\mathrm{LSCF}$ at various ratios at $800^{\circ} \mathrm{C}$ for $2 \mathrm{~h}$ in air. The fusion resulted in the formation of $\mathrm{NaLa}_{9}\left(\mathrm{SiO}_{4}\right)_{6} \mathrm{O}_{2}$ (NLSO) or $\mathrm{La}_{9.33}\left(\mathrm{SiO}_{4}\right)_{6} \mathrm{O}_{2}$ (LSO) phase in the vicinity of the interface between LSCF and NS particles. LSO has apatite structure and NLSO is obtained by dissolved sodium at La sites of LSO. NSLO or LSO would be a bonding phase formed at the interface between LSCF and silicate sealing sheets by the fusion at $800^{\circ} \mathrm{C}$. Gas-tight sealing with high electrical resistance and high stability for a long time requires appropriate bonding phases. Some researchers reported that electrical properties of LSO and $\mathrm{Na}$ doped LSO have low electronic conductivity and oxygen ionic conductivity at high temperatures, but they much depend on the compositions [11-13].

NS particles and LSCF were mixed at various ratios again and fused at $800^{\circ} \mathrm{C}$. The XRD peak ratio of (211) of LSO or NLSO to (111) of Si was estimated for the various fused powders. Figure 2 shows relationship between the XRD ratio and composition of the fused powder. All NS particles contained $\mathrm{Si}$ at the molar ratio of $\mathrm{Na} / \mathrm{Si}=0.63$. This relationship was estimated in terms of $\mathrm{Na} /(\mathrm{Na}+\mathrm{La})$ ratio, but $\mathrm{Si}$ also contained at the same ratio of $\mathrm{Na} / \mathrm{Si}=0.63$ for all the fused powder. This figure shows that (211) peak was increased with increasing $\mathrm{Na} /(\mathrm{Na}+\mathrm{La})$ ratio and reached maximum peak intensity at about $\mathrm{Na} /(\mathrm{Na}+\mathrm{La})=0.1 . \quad \mathrm{Na} /(\mathrm{Na}+\mathrm{La})$ ratio in an NLSO molecular is 0.1 , whereas $\mathrm{Si} /(\mathrm{Si}+\mathrm{La})$ ratio in NLSO and LSO is 0.4 and 0.39 , respectively. If the peak ratio was dependent of amount of $\mathrm{Si}$ in the fused powder, the relationship will show a maximum value in the $\mathrm{Na}(\mathrm{Na}+\mathrm{La})$ range of 0.4-0.6. Thus, the maximum XRD peak at $\mathrm{Na} /(\mathrm{Na}+\mathrm{La})$ ratio of 0.1 would conclude the (211) peak of Figure 1 was identified as NLSO instead of LSO, and the bonding phase between LSCF and the silicate sealing was NLSO.

NLSO bonding phase was obtained in the vicinity of interface between LSCF and fused sealing sheet when 


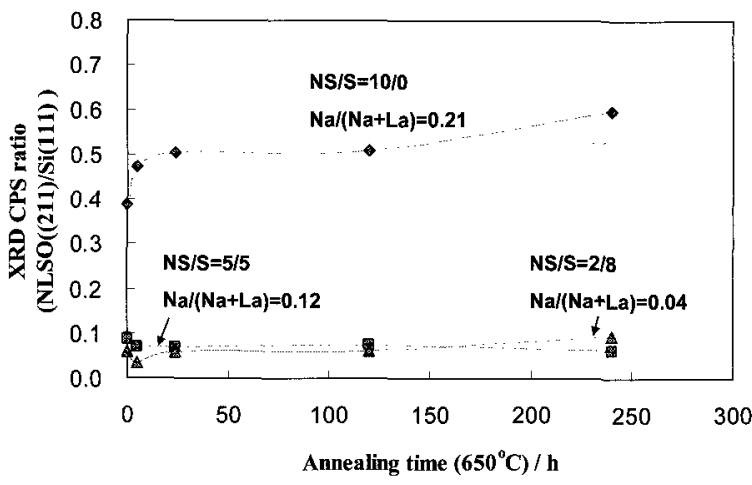

Figure 3. Change in the amount of NLSO phase with sintering time.

the sheet was prepared with NS particles. The effects of addition of $S$ particles in the sheets on the formation of NLSO bonding phase and the change in the amount of NLSO phase with sintering time were then investigated by preparing the sealing sheets composed NS particles and $\mathrm{S}$ particles at various ratios. Figure 3 shows the change in the relative amount ratio of NLSO phase with sintering time at $650^{\circ} \mathrm{C}$. The sheets synthesized with only NS particles resulted in NLSO formation at the NLSO/Si ratio of 0.4 and slightly increased with time sintering at $650^{\circ} \mathrm{C}$. The increase in NLSO phase during sintering at $650^{\circ} \mathrm{C}$ will lead to degradation of gas-tight seal during SOFC working. However, the addition of $\mathrm{S}$ particle much suppressed the formation of NLSO phase. The amount of the NSLO phase was determined by the fusion at $800^{\circ} \mathrm{C}$ for $2 \mathrm{~h}$ and the NSLO formation was independent of the time sintering at $650^{\circ} \mathrm{C}$ for $250 \mathrm{~h}$.

\section{LSCF-NS}
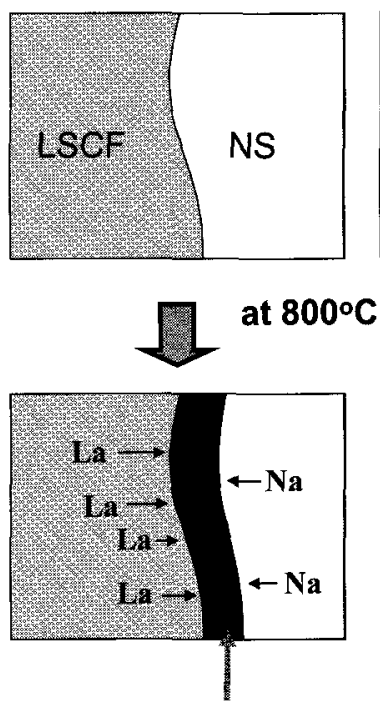

NLSO

\section{LSCF-NS/S}

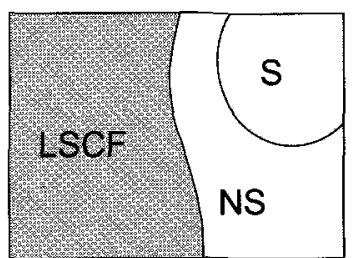

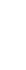
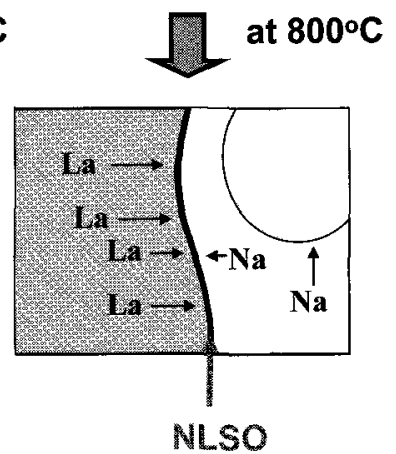

Figure 4. Schematic illustrations of NLSO phase formation.

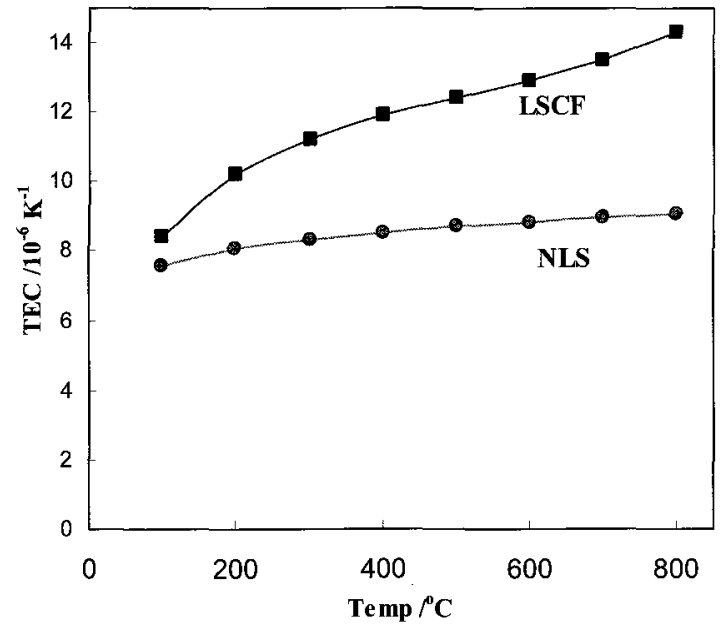

Figure 5. Temperature dependence of thermal expansion coefficients for LSCF and NLSO.

The fused powder containing NS particles and $S$ particles at the NS/S ratio of $1 / 1$ is estimated at the $\mathrm{Na} /(\mathrm{Na}+\mathrm{La})$ composition of 0.12 , whereas the powder containing only NS particles is estimated at $\mathrm{Na} /(\mathrm{Na}+\mathrm{La})$ $=0.21$. Figure 2 showed that the relationship between the NLSO formation and the composition had a maximum value at about $\mathrm{Na} /(\mathrm{Na}+\mathrm{La})=0.1$. Thus, the suppression of NLSO phase was caused by not only the $\mathrm{Na} /(\mathrm{Na}+\mathrm{La})$ composition in the bused powder but also the effect of addition of $S$ particles.

The addition of $S$ particles led to suppress the penetration into the porous LSCF [10]. The penetration of the sealing materials into the LSCF actually changed the contact area between LSCF and the sealing materials. This relationship between the bonding phase and the NS/S ratios was examined using powders. Therefore, if even the contact area is unchanged, the NLSO bonding phase was depressed by the addition of S particle.

The depression mechanism is still vague, but we suggest as follows. Figure 4 shows schematic illustration of NLSO bonding phase formation. Thick NLSO phase was formed in the vicinity of interface between LSCF and NS particles because lanthanum and sodium are diffused toward the interface. When $S$ particles were added in NS particles, sodium would be diffused the interfaces both between LSCF and NS particles and between NS particle and S particles. Both the sodium diffusion led to insufficient supply to form thick NLSO phase in the interface between LSCF and NS particles. The diffusion of sodium at the interface between NS and S particles would also result in partial fusion at the surface of $S$ particle at relative low temperatures. The sodium diffusion toward $\mathrm{S}$ particles would lead to form continual gradation of sodium in the vicinity of NS/S interface, and this gradient interface would much depress crack or separation in the interface.

SOFCs are generally exposed to thermal cycles between room temperatures and $650-800^{\circ} \mathrm{C}$. The severe thermal cycles often result in critical crack in the 
vicinity of sealing interfaces. Thermal expansion of NLSO phase was also investigated as shown in Figure 5. Temperature dependence of thermal expansion coefficient (TEC) for some glasses showed anomalous profiles at glass transition temperatures [14], and the anomalous profile would lead to form cracks or separation between glasses and ceramics. The TEC of NLSO was slightly increased with increasing temperature and it did not show the anomalous behavior. ETC mismatch between LSCF and NLSO was relatively large, but NLSO that have no glass transition was applicable for the bonding phase of silicate glass sealing materials.

\section{CONCLUSION}

Insulating flexible sheets were developed to realize gas-tight sealing against porous LSCF. The sheets composed of NS particles and $\mathrm{S}$ particles were fused at $800^{\circ} \mathrm{C}$ for $2 \mathrm{~h}$ and sintered at $650^{\circ} \mathrm{C}$ for $240 \mathrm{~h}$. The formation of bonding phase and change in the amount of the bonding phase were investigated in order to develop highly stable gas-tight sealing materials for electrode-supported SOFCs. Fusion of the sheet on porous LSCF ceramics at $800^{\circ} \mathrm{C}$ resulted in gas-tight sealing and simultaneously formation of NLSO. The addition of $\mathrm{S}$ particles suppressed the formation of NLSO bonding phase as well as suppression of the penetration into the porous LSCF. TEC of NLSO slightly increased with increasing temperature and did not show anomalous profile, which shows for some glasses at glass transition temperatures. The anomalous behavior often result in severe cracks or separation between sealing materials and ceramics, and then the NLSO phase would be valuable as the bonding phase between LSCF and glass seals.

\section{ACKNOWLEDGEMENT}

This work was supported by NEDO as part of the Advanced Ceramic Reactor Project.

\section{REFERENCES}

[1] K. Kendall, N. Q. Minh, S. C. Singhal, "High Temperature Solid Oxide Fuel Cells", Ed. By S. C. Singhal and K. Kendall, Elsevier, Oxford (2003) pp. 197-209.

[2] N. Q. Minh, J. Am. Ceram. Soc., 76, 563-588 (1993).

[3] S. Suda, K. Kawahara, K. Jono, J. Ceram. Soc Japan; in preparation.

[4] S. Suda, M. Iwaida, K. Yamashita, T. Umegaki, $J$. Non-Cryst. Solids, 197, 65-72 (1996).

[5] S. Suda, T. Yoshida, K. Kanamura, T. Umegaki, J. Non-Cryst. Solids, 321, 2-9 (2003).

[6] W. Stöber, A. Fink, E. Bohn, J. Colloid Interf.Sci., 109, 62-69 (1968).

[7] Z. Shao, S. M. Haile, Nature, 431, 170-173 (2004).

[8] E. P. Murray, M. J. Sever, S. A. Barnett, Solid State Ionics, 148, 27-34 (2002).

[9] E. P. Murray, S. A. Barnett, "Solid Oxide Fuel Cells VI", Ed. By S. C. Singhal, and M. Dokiya, The Electrochemical Society, Inc., Pennington (1999) pp. 369-378.

[10] S. Suda, K. Kawahara and K. Jono, ECS Transaction; in received.

[11] S. Nakayama, M. Sakamoto, J. Euro. Ceram. Soc.,
$18,1413-1418(1998)$.

[12] M. Higuchi, Y. Masubuchi, S. Nakayama, S. Kikkawa, K. Kodaira, Solid State Ionics, 174, 73-80 (2004).

[13] A. A. Yaremchenko, A. L. Shaula, V. V. Kharton, J. C. Waerenborgh, D. P. Rojas, M. V. Patrakeev, F. M. B. Marques, Solid State Ionics, 171, 51-59 (2004).

[14] W. D. Kingery, H. K. Bowen, D. R. Uhlmann, "Introduction to Ceramics", John Wiley \& Sons,Inc. (1976) pp. 595-603.

(Received December 10, 2006;Accepted January 31, 2007) 